\title{
Repeatability of apparent diffusion coefficient and intravoxel incoherent motion parameters at 3.0 Tesla in orbital lesions
}

\author{
Augustin Lecler $^{1,2}$ (i) - Julien Savatovsky ${ }^{1} \cdot$ Daniel Balvay $^{2} \cdot$ Mathieu Zmuda $^{3}$. \\ Jean-Claude Sadik $^{1}$ - Olivier Galatoire ${ }^{3}$. Frédérique Charbonneau ${ }^{1}$. Olivier Bergès ${ }^{1}$. \\ Hervé Picard $^{4} \cdot$ Laure Fournier ${ }^{2,5}$
}

Received: 15 February 2017 /Revised: 6 June 2017 / Accepted: 7 June 2017 / Published online: 4 July 2017

(C) The Author(s) 2017. This article is an open access publication

\begin{abstract}
Objectives To evaluate repeatability of intravoxel incoherent motion (IVIM) diffusion-weighted imaging (DWI) parameters in the orbit.

Methods From December 2015 to March 2016, 22 patients were scanned twice using an IVIM sequence with $15 \mathrm{~b}$ values $\left(0-2,000 \mathrm{~s} / \mathrm{mm}^{2}\right)$ at 3.0T. Two readers independently delineated regions of interest in an orbital mass and in different intraorbital and extra-orbital structures. Short-term test-retest repeatability and inter-observer agreement were assessed using the intra-class correlation coefficient (ICC), the coefficient of variation (CV) and Bland-Altman limits of agreements (BA-LA). Results Test-retest repeatability of IVIM parameters in the orbital mass was satisfactory for ADC and D (mean CV $12 \%$ and $14 \%$, ICC $95 \%$ and $93 \%$ ), poor for $f$ and $\mathrm{D}^{*}$ (means CV $43 \%$ and $110 \%$, ICC $90 \%$ and $65 \%$ ). Inter-
\end{abstract}

Electronic supplementary material The online version of this article (doi:10.1007/s00330-017-4933-6) contains supplementary material, which is available to authorized users.

Augustin Lecler

alecler@for.paris

1 Department of Radiology, Fondation Ophtalmologique Adolphe de Rothschild, 29 rue Manin, 75019 Paris, France

2 Université Paris Descartes Sorbonne Paris Cité, INSERM UMR-S970, Cardiovascular Research Centre - PARCC, Paris, France

3 Department of Orbitopalpebral Surgery, Fondation Ophtalmologique Adolphe de Rothschild, Paris, France

4 Clinical Research Unit, Fondation Ophtalmologique Adolphe de Rothschild, Paris, France

5 Assistance Publique-Hôpitaux de Paris, Hôpital Européen Georges Pompidou, Radiology Department, Université Paris Descartes Sorbonne Paris Cité, Paris, France observer repeatability agreement was almost perfect in the orbital mass for all the IVIM parameters (ICC $=95 \%, 93 \%$, $94 \%$ and $90 \%$ for ADC, D, $f$ and $\mathrm{D}^{*}$, respectively).

Conclusions IVIM appeared to be a robust tool to measure D in orbital lesions with good repeatability, but this approach showed a poor repeatability of $f$ and $\mathrm{D}^{*}$.

Key Points

- IVIM technique is feasible in the orbit.

- IVIM has a good-acceptable repeatability of D (CV range $12-25 \%)$.

- IVIM interobserver repeatability agreement is excellent (ICC range 90-95\%).

- for $D^{*}$ provide higher test-retest and interobserver variabilities.

Keywords IVIM $\cdot$ MRI $\cdot$ DWI $\cdot$ Orbit $\cdot$ Feasibility

$\begin{array}{ll}\text { Abbreviations } \\ \text { ADC } & \text { Apparent diffusion coefficient } \\ \text { BA-LA } & \text { Bland-Altman limits of agreements } \\ \text { CV } & \text { Coefficient of variation } \\ \text { D* } & \text { Pseudodiffusion coefficient } \\ \text { D } & \text { 'True' diffusion coefficient } \\ \text { DWI } & \text { Diffusion-weighted imaging } \\ f & \text { Perfusion fraction } \\ \text { ICC } & \text { Intra-class correlation coefficient } \\ \text { IVIM } & \text { Intravoxel incoherent motion } \\ \text { MRI } & \text { Magnetic resonance imaging } \\ \text { ROI } & \text { Region of interest }\end{array}$

\section{Introduction}

Diffusion-weighted imaging (DWI) using magnetic resonance imaging (MRI) was described by Le Bihan in 1986 as being 
sensitive to displacement of water protons in tissues due to both random Brownian motion as well as capillary perfusion $[1,2]$. Intravoxel incoherent motion (IVIM) imaging uses multiple $b$ values with a biexponential model to quantify both phenomena. The DW signal is the result of a 'pure' diffusion fraction and a perfusion-dominated pseudo-diffusion fraction, yielding three parameters: the 'pure' diffusion coefficient (D), the perfusion fraction $(f)$ and the pseudo-diffusion coefficient (D*) [1].

$$
S(b)=S(0)\left[f e^{-b D^{*}}+(1-f) e^{-b D}\right]
$$

This model has been shown to provide a pertinent description of the DW signal measured in highly vascular organs [3]. Due to both improvement of MR devices and post-treatment softwares, IVIM has become more available in clinical practice. It has been tested and proved useful in a variety of organs, such as prostate, liver, abdomen, kidney and pelvis, and also in the head and neck [4-8], to diagnose liver diseases, characterise tumours, or assess and monitor tissue response to treatment [4-8]. However, one issue is repeatability, which has been evaluated over time in brain imaging $[9,10]$ or abdominal imaging [11-15].

In the orbit, only a few studies evaluated the DWI, showing its usefulness when visualising and diagnosing tumours [16, 17]. An ADC value $<110^{-3} \mathrm{~s} / \mathrm{mm}^{2}$ at $\mathrm{b}=1,000 \mathrm{~s} / \mathrm{mm}^{2}$ were considered optimal thresholds to predict overall malignancy [17] and a low ADC $<0.610^{-3} \mathrm{~s} / \mathrm{mm}^{2}$ at $\mathrm{b}=1,000 \mathrm{~s} / \mathrm{mm}^{2}$ was reported to have good accuracy in distinguishing benign from malignant orbital lymphoproliferative disorders [18]. Also, two recent studies combining morphological characteristics to DWI and dynamic contrast-enhanced perfusion showed that ADC alone yielded the optimal sensitivity in differentiating malignant from benign orbital lymphoproliferative disorders [19, 20]. However, IVIM has never been tested in the orbits, and it makes sense to test IVIM repeatability in orbital anatomy/disease in order to understand technical limitations before its use in future studies.

The aim of our study was to prospectively evaluate robustness of IVIM-derived parameters in the orbit by evaluating the short-term test-retest and inter-observer repeatability of IVIM parameters and apparent diffusion coefficient (ADC) of orbital lesions and normal intra-orbital and extra-orbital structures at $3.0 \mathrm{~T}$.

\section{Materials and methods}

\section{Study design}

We conducted a prospective study in a tertiary referral centre specialising in ophthalmic diseases (NCT02401906). This study was prospectively approved by our institutional
Research Ethics Board and adhered to the tenants of the Declaration of Helsinki (IRB 2015-A00364-45). Signed informed consent was obtained from all subjects.

From December 2015 through March 2016, 22 patients were included in the study. Inclusion criteria were: (a) age over 18 years; (b) presence of an orbital mass. Patients with an MR contraindication such as implanted pacemakers, the presence of other metallic foreign bodies or claustrophobia were excluded.

\section{MR imaging}

All MRIs were performed on the same 3 Tesla Philips INGENIA device with a 32-channel head coil (Philips Medical Systems, Best, The Netherlands). All patients had the same MRI protocol including two IVIM acquisitions acquired with $15 \mathrm{~b}$ values, ranging from 0 to $2,000 \mathrm{~s} / \mathrm{mm}^{2}$. The $\mathrm{b}$ values distribution was chosen to cover both the initial pseudodiffusion decay $\left(\leq 200 \mathrm{~s} / \mathrm{mm}^{2}\right)$ and the molecular diffusion decay $\left(>200 \mathrm{~s} / \mathrm{mm}^{2}\right)$. We used a large number of lower $\mathrm{b}$ values for more accurate calculation of IVIM parameters. The first acquisition was acquired at the beginning of the examination and the second one immediately before contrast injection, with a median delay between the two scanning procedures of $17 \mathrm{~min}$, providing two distinct data sets of IVIM. Patients were asked to look at a fixed point during the acquisitions in order to prevent kinetic artefacts generated from eye movements. They were also asked to move between the two sequences and were repositioned for the second IVIM acquisition. Technical specifications of the MRI protocol are provided in Table 1.

Table 1 Specifications of the intravoxel incoherent motion (IVIM) sequence parameters

\begin{tabular}{ll}
\hline IVIM & \\
\hline TR/TE (ms) & $2,639 / 74$ \\
Section thickness (mm) & 3 \\
Number of slices & 210 \\
Gap (mm) & 1 \\
Bandwith (Herz) & 1,695 \\
Number of excitations & 1 \\
Number of b-values & 15 \\
b values (s/mm ${ }^{2}$ ) & $0,10,20,40,80,110,140,170,200,300$, \\
& \multicolumn{1}{c}{$400,600,800,1,000,2,000$} \\
Field of view (mm ${ }^{2}$ ) & $122 \times 122$ \\
Matrix & $176 \times 122$ \\
Parallel acceleration factor & SENSE =2 \\
Acquisition duration (s) & 143 \\
\hline
\end{tabular}




\section{Image analysis}

Two radiologists, blinded to patient ID, medical history and laboratory results, read independently and in random order the IVIM sequences. The first senior neuroradiologist was specialized in orbital imaging with 7 years of experience (AL), and the second was a senior radiologist with no experience in orbital imaging (LF).

All the post-processing steps were performed using the Olea Sphere ${ }^{\circledR}$ software (v3.0, Olea Medical, La Ciotat, France), implementing a Bayesian probability-based algorithm using all $15 \mathrm{~b}$-values to fit a biexponential diffusion model to each voxel within a region of interest (ROI) for the calculation of IVIM parameters (D, $\mathrm{D}^{*}$ and $f$ ), and a monoexponential diffusion model for the calculation of ADC (Fig. 1).

The operators independently drew seven ROIs on each imaging set: two ROIs inside the orbital mass, the first one encompassing the maximum area of the orbital mass (ROI 1) and the second one a circular ROI at the centre of the orbital mass without consideration for the zones with restricted diffusion or with enhancing nodules if present (ROI 2) (Fig. 1), three ROIs in non-tumoral orbital structures: in the contralateral lacrymal gland (ROI 3), in the contralateral medial (ROI 4) and lateral (ROI 5) extra-ocular muscles, and two ROIs outside the orbit: one ROI in the temporal muscle (ROI 6) and one ROI in the contralateral temporal lobe white matter (ROI 7). The five last ROIs were drawn in order to analyse their repeatability, in case they might be used in further studies as structures of reference to normalise IVIM values (as is done sometimes in brain studies [10,21]). Size and location of the ROIs in the orbital and encephalic locations was kept constant across patients to every possible extent, except for ROI 1 , which encompassed the largest possible portion of the mass on the slice including its largest diameter. ROIs were placed on the transverse b0 image and propagated to all $b$-values, ADC and IVIM parametric maps. Readers were free to review the other structural images to ease the drawing of the ROI. A direct registration between the structural and the IVIM images was not possible due to the distortions seen on the IVIM images.

In addition, given that parallel imaging was used for DWI, we used the difference method to estimate the signal to noise ratio (eSNR) in the orbital mass [22].

\section{Statistical analysis}

Data were analysed using the $\mathrm{R}$ software package ( $\mathrm{R}$ Foundation for Statistical Computing, Vienna, Austria). Mean IVIM values and CVs were computed for each reader individually, then averaged for both readers. Test-retest repeatability of IVIM parameters was assessed by calculating the coefficient of variation $(\mathrm{CV}$, computed as standard deviation
(SD) divided by the mean), the intra-class correlation coefficient (ICC), and the 95\% Bland-Altman limits of agreements (BA-LA) $[23,24]$ for each reader individually, then averaged for both readers, as per the recommendations of the Quantitative Imaging Biomarkers Alliance (QIBA) [25]. The parameters' repeatability was defined as excellent when $\mathrm{CV}$ was $\leq 10 \%$, good when $\mathrm{CV}$ was between $10-20 \%$, acceptable when CV was between $20-30 \%$, and poor when CV was $>30 \%$ [24]. The inter-observer repeatability agreement was assessed by calculating the ICC and was interpreted as follows: $0.0-0.2$ :poor correlation; $0.21-0.4$ :fair correlation ;0.41-0.6:moderate correlation ; 0.61-0.8:good correlation ;0.81-1:almost perfect correlation [23].

\section{Results}

Twenty-two consecutive patients were included in the study (nine males and 13 females, median age 51 years, range $41-$ 62). Six patients had a histologically-proven orbital lymphoma, six patients had an orbital inflammation, four patients had a cavernous haemangioma, two had a dacryoadenitis, two had an orbital metastasis, one had a muscular granuloma and one had an orbital sarcoma. The quality of ADC and IVIM parametric maps was considered good for subsequent analysis for all patients, and no patient had to be secondarily excluded from the study because of artefacts masking or distorting orbital tumours.

Mean (SD) ROI size was 86 (36) pixels for ROI 1, 23.5 (9) for ROI 2, 21 (9) for ROI 3, 27 (10) for ROI 4, 22.5 (8) for ROI 5, 127.5 (48) for ROI 6 and 601 (114) for ROI 7.

Mean (SD) IVIM parameter values inside all orbital lesions were calculated as follows: $1.26(0.35), 1.02(0.27), 0.18$ $(0.07)$ and 14.6 (7.9) for $\mathrm{ADC}, \mathrm{D}, f$ and $\mathrm{D}^{*}$, respectively. The mean IVIM parameters values and SDs inside the other ROIs are shown in Table 2. The average eSNR inside the orbital mass at $b=2,000 \mathrm{~s} / \mathrm{mm}^{2}$ was 56.6 (SD 3.5)

\section{Test-retest repeatability}

Repeatability of IVIM parameters in the orbital mass was good for ADC and D (mean CV 12\% and 14\%, ICC 95\% and $93 \%$, BA-LA : $[-0.35 ; 0.35]$ and $[-0.36 ; 0.27])$ and poor for $f$ and $\mathrm{D} *$ (mean $\mathrm{CV} 43 \%$ and $110 \%$, ICC $90 \%$ and $65 \%$, BA-LA : $[-0.10 ; 0.10]$ and $[-23.1 ; 20.9]$ ) (Fig. 2.a). There was a significant correlation between $\mathrm{ADC}$ and $\mathrm{D}$ values in the orbital mass $(\mathrm{p}<0.001)$.

Regarding the structures which could be used as references, repeatability was good in the lacrymal gland for ADC and D (mean CV $18 \%$ and $19 \%$, ICC $94 \%$ and $86 \%$, BA-LA : $[-0.61 ; 0.75]$ and $[-0.36 ; 0.45])$, poor for $f$ and $\mathrm{D} *($ mean CV $51 \%$ and $130 \%$, ICC $91 \%$ and $75 \%$, BA-LA : [ -0.09 ; $0.10]$ and $[-17.6 ; 12.0])$. Repeatability was acceptable in the 


\section{a}

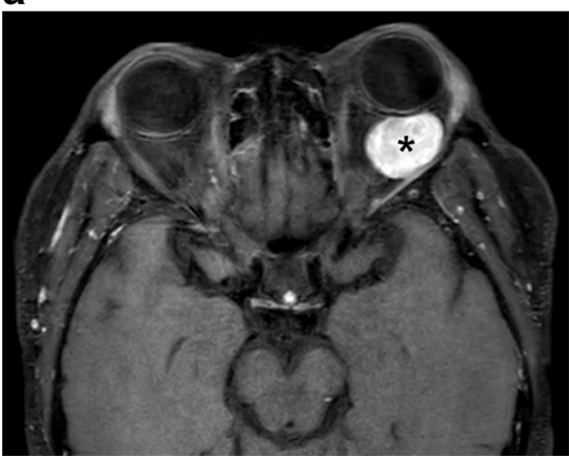

b

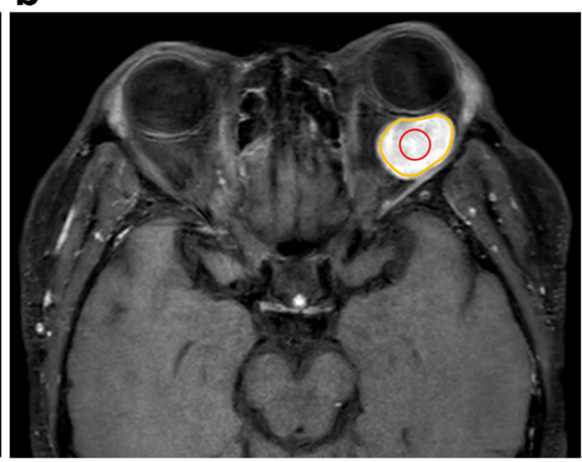

d

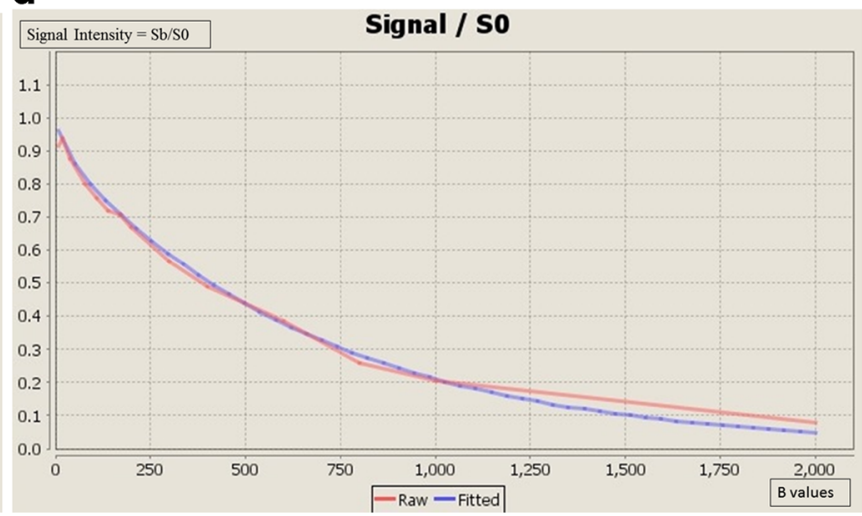

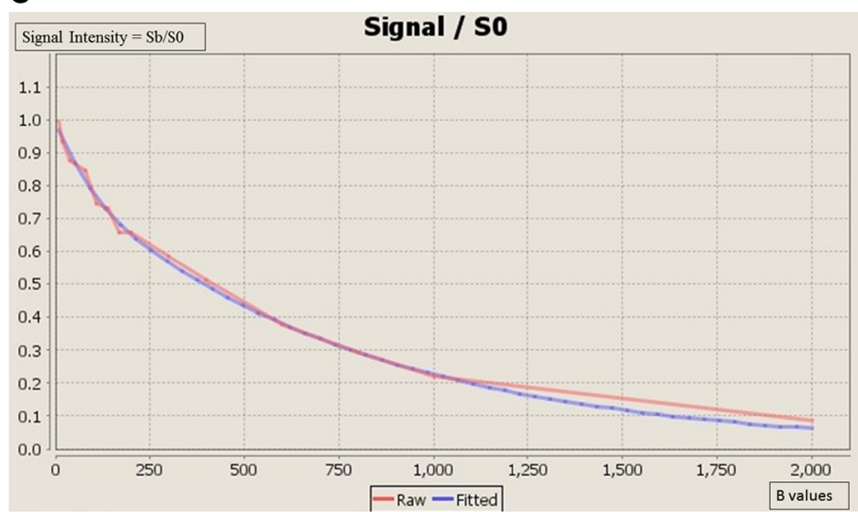

e
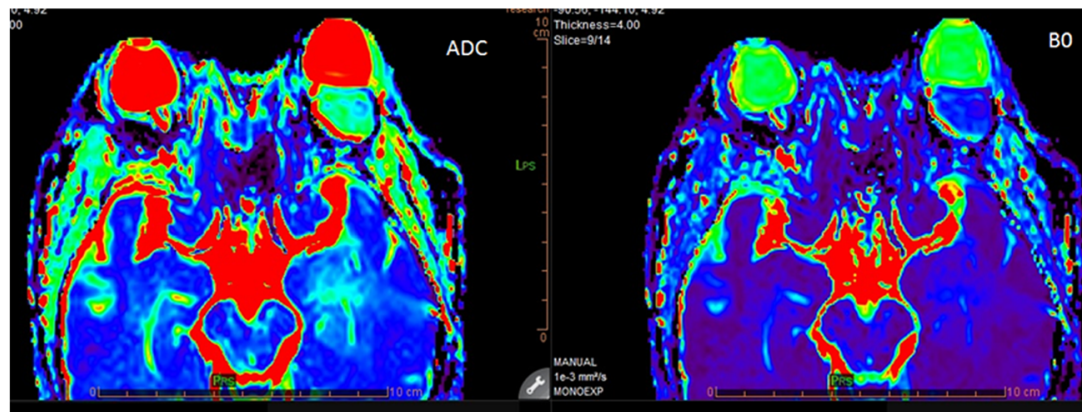

BO

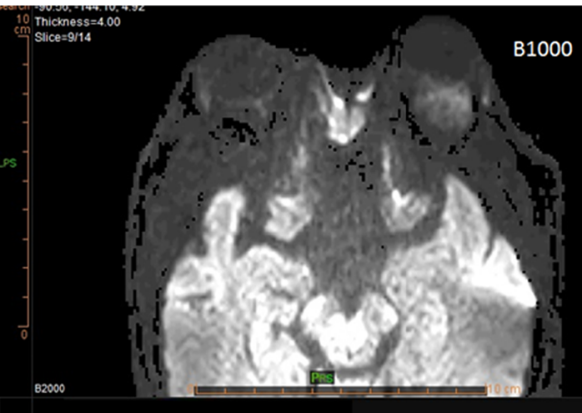

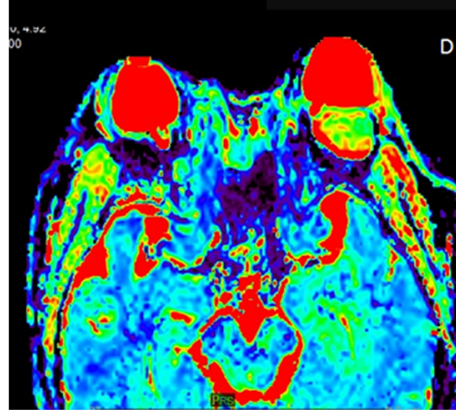

Fig. 1 A 47-year-old man with a cavernous haemangioma in his left orbit (asterisk), displacing the eye anteriorly, as shown on the axial postcontrast T1 WI (a). Placement of a freehand large region of interest (ROI) (yellow line) and of a circular small ROI (red circle) inside the mass are shown (b). Test (c) and retest (d) bi-exponential fitting curves using $b$ values are shown. Coloured intravoxel incoherent motion (IVIM) parametric map is displayed (e)

\section{Inter-observer repeatability}

Inter-observer repeatability was almost perfect in the orbital mass $(\mathrm{ICC}=95 \%, 93 \%, 94 \%$ and $90 \%$ and $\mathrm{BA}-\mathrm{LA}=[-0.30$; detailed values are shown in Table 3. 
Table 2 Mean intravoxel incoherent motion (IVIM) parameter values (of all measurements)

Mean values

\begin{tabular}{lllll}
\hline Anatomical region & $\mathrm{ADC}\left(10^{-3} \mathrm{~s} / \mathrm{mm}^{2}\right)(\mathrm{SD})$ & $\mathrm{D}\left(10^{-3} \mathrm{~s} / \mathrm{mm}^{2}\right)(\mathrm{SD})$ & $f(\%)(\mathrm{SD})$ & $\mathrm{D} *\left(10^{-3} \mathrm{~s} / \mathrm{mm}^{2}\right)(\mathrm{SD})$ \\
ROI 1. Freehand large ROI inside the mass & $1.26(0.35)$ & $1.02(0.27)$ & $0.18(0.07)$ & $14.6(7.9)$ \\
ROI 2. Circular small ROI inside the mass & $1.25(0.38)$ & $1.02(0.3)$ & $0.17(0.08)$ & $14.2(9.4)$ \\
ROI 3. Lacrymal gland & $1.5(0.68)$ & $1.13(0.28)$ & $0.2(0.08)$ & $15.4(7.8)$ \\
ROI 4. Medial extra-ocular muscle & $1.74(0.57)$ & $1.27(0.21)$ & $0.21(0.08)$ & $11.6(5.1)$ \\
ROI 5. Lateral extra-ocular muscle & $1.54(0.27)$ & $1.17(0.21)$ & $0.2(0.06)$ & $9.8(4.9)$ \\
ROI 6. Temporal muscle & $1.63(0.29)$ & $1.16(0.13)$ & $0.23(0.07)$ & $14.6(5.6)$ \\
ROI 7. Temporal lobe & $0.89(0.07)$ & $0.75(0.04)$ & $0.13(0.05)$ & $20.2(6.7)$ \\
\hline
\end{tabular}

$A D C$ apparent diffusion coefficient, $D$ 'true' diffusion coefficient, $D^{*}$ pseudodiffusion coefficient, $f$ perfusion fraction, $S D$ standard deviation, $R O I$ region of interest

$0.29],[-0.260 .27],[-0.06 ; 0.07]$ and $[-10.5 ; 8.6]$ for ADC, $\mathrm{D}, f$ and $\mathrm{D}^{*}$, respectively) (Fig. 2.b). It was almost perfect in the lacrymal gland for all the IVIM parameters (ICC $=80 \%$, $84 \%, 90 \%$ and $84 \%$ and BA-LA $=[-0.56 ; 0.44],[-32 ; 0.23]$, $[-0.06 ; 0.10]$ and $[-12.3 ; 12.1]$ for $\mathrm{ADC}, \mathrm{D}, f$ and $\mathrm{D}^{*}$, respectively). It was almost perfect in the extra-ocular muscles and the temporal muscle for ADC, almost perfect in the lateral extra-ocular muscle and the temporal muscle for $\mathrm{D}$ and in the temporal muscle for $f$. This level of inter-observer repeatability was only seen for the extra-ocular muscles and the temporal muscle for D* (Supplementary Fig. 2). All detailed values are shown in Table 4.

\section{Discussion}

Our study allowed evaluation of the robustness of quantitative assessment of IVIM parameters in the orbit. Test-retest repeatability of IVIM in the orbital tumours was good for ADC and $\mathrm{D}$, but was poor for $f$ and especially $\mathrm{D}^{*}$. Inter-observer repeatability agreement was almost perfect for all IVIM values in orbital tumours.

Our study was compliant with the Quantitative Imaging Biomarkers Alliance (QIBA) guidelines [25-27] to best evaluate technical performance of IVIM in orbital imaging. IVIM is a relatively new imaging technique and seems promising in the characterisation and evaluation of tumours, but proportionally few studies have evaluated its accuracy, repeatability or reproducibility. Therefore, we decided to perform a study to quantify the variability and possible source of error related to the technique in the orbit before further evaluation of its clinical relevance or impact in clinical practice [26, 27].

DWI and ADC repeatability have already been evaluated over time in head and neck or brain imaging [21,28], but only few studies have evaluated the IVIM repeatability in these domains $[9,10]$ and none in the orbit to the best of our knowledge. A large majority of previously published studies evaluating the IVIM accuracy, repeatability or reproducibility were performed in the abdomen, especially in the liver. They showed a higher repeatability for $\mathrm{ADC}$ and $\mathrm{D}$ parameters than for perfusion-related $f$ and $\mathrm{D}^{*}$ parameters. The pseudodiffusion coefficient $\mathrm{D}^{*}$ appeared to be the least reproducible parameter among IVIM metrics, with the coefficient of variation ranging from $24.8 \%$ to $193.8 \%$ [11-14, 29], whereas the true diffusion coefficient $\mathrm{D}$ appeared to be the most reproducible parameter in the liver and in the kidney [14, 30, 31]. Although a recent multicentre study showed significant discrepancies of IVIM values between different MR imagers across multiple centres [15], studies evaluating the use of this technique in the abdomen concluded that IVIM parameters could be clinically relevant $[14,30,31]$. Our results are in agreement with these studies, with an acceptable test-retest repeatability for $\mathrm{D}$ in both orbital and extra-orbital structures (mean 22\%, range 14-29\%) similar to ADC (mean 22\%, range $12-33 \%$ ), and a poor repeatability for $f$ and $\mathrm{D}^{*}$ (mean $57 \%$, range $43-75 \%$ and mean $130 \%$, range $110-160 \%$ ) [14, 30, 31]. A few hypotheses may explain these results. First, the IVIM model results from an oversimplification as it does not consider the exchanges between intra and extra-vascular compartments nor the possibility of a diffusion anisotropy and it does not distinguish arterial from venous flows, which may impair the accurate estimation of the two parameters related to blood flow, $f$ and $\mathrm{D}^{*}[2,32]$. Second, blood water comprises less than $5 \%$ of the total tissue water in the orbit as in many organs, therefore most of the IVIM signal arises from extravascular water and hence is theoretically uninformative in assessing blood flow by the IVIM method. The dynamic range for the measurement of $f$ and $\mathrm{D}^{*}$ is poor and the quality of parameter estimates depends upon a number of factors including the number of $b$ values obtained, especially of low $b$ values, and the signal-to-noise ratio, which has to be high enough, therefore requiring a high-field MRI [32]. Third, there is no direct measurement of the IVIM parameters but different methods to calculate them from exponential decay 
a

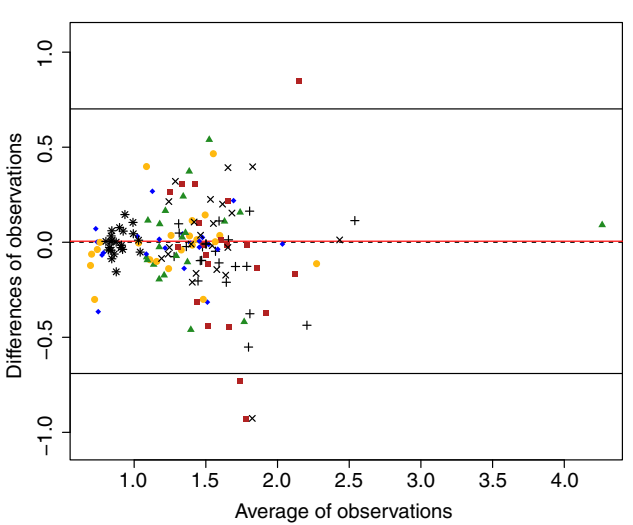

DSTAR

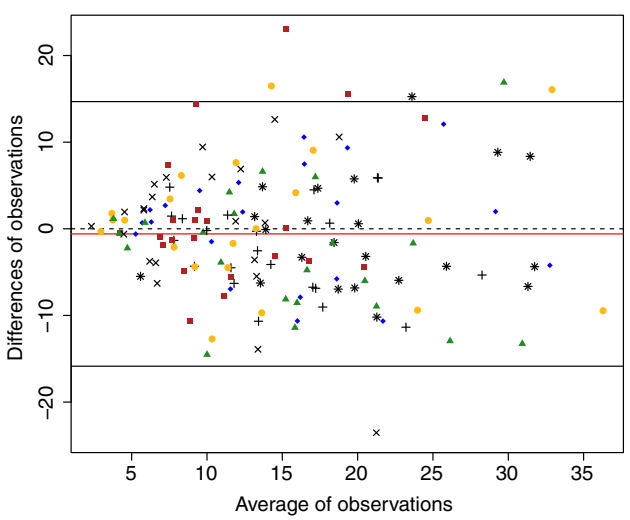

b

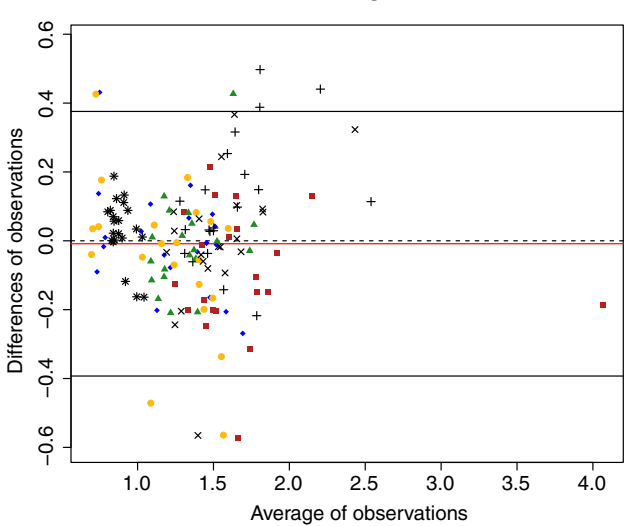

DSTAR

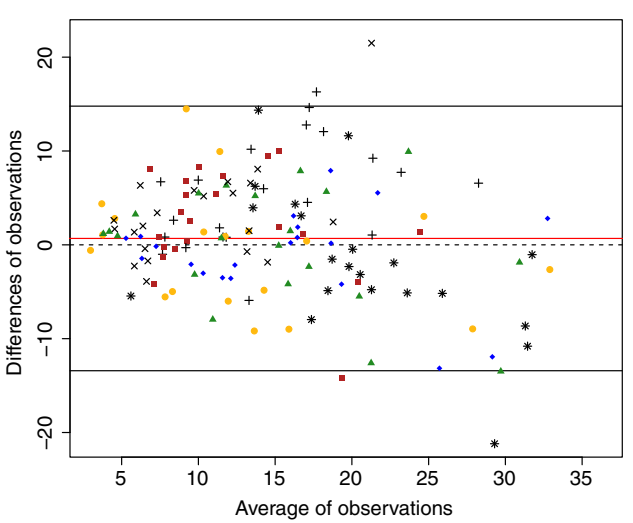

D

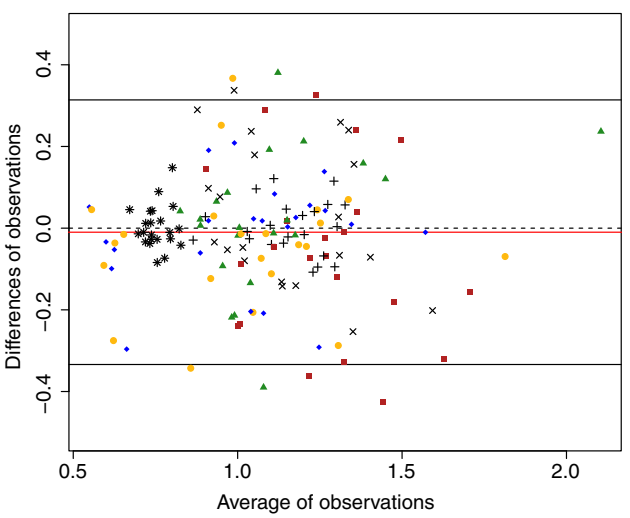

FIVIM

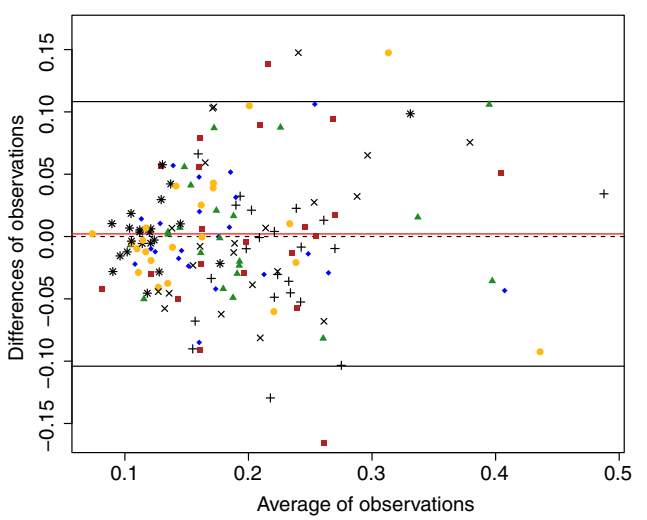

D

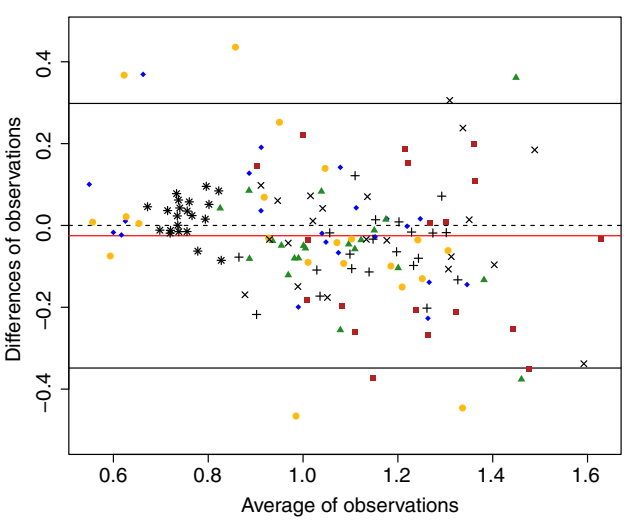

FIVIM

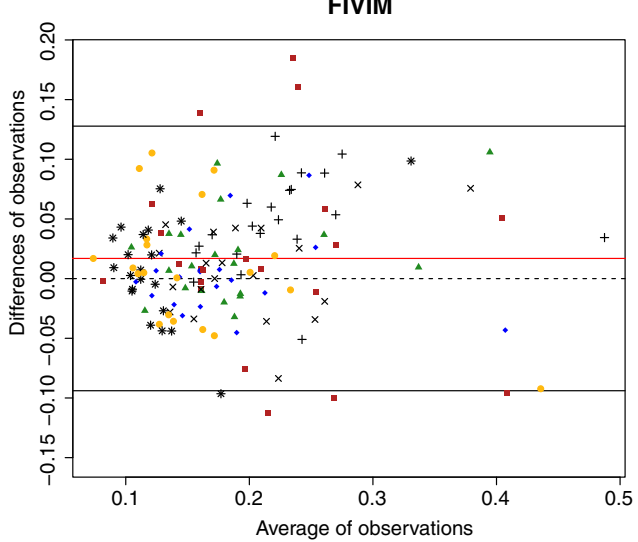


Fig. 2 Bland-Altman plots showing test-retest repeatability (a) and interobserver repeatability agreement (b) of apparent diffusion coefficient $(\mathrm{ADC})$, 'true' diffusion coefficient $(D)$, pseudodiffusion coefficient $\left(D^{*}\right)$, perfusion fraction $(f)$, for all regions of interest (ROIs)

data, such as the nonlinear least squares or the Bayesian probability theory. Although reported to be more accurate, the Bayesian approach provides only a representation of the uncertainty in the parameters estimates in the form of a probability density function [33].

ADC and D fulfil the QIBA quality criteria [34]. In the literature, a $20 \%$ within-subject coefficient of variation is considered as a good threshold to use a biomarker in a clinical practice, because it suggests that a change of approximately $40 \%$ is required in a single subject to be considered that this difference may be related to a biological mechanism and not to the intrinsic variability of the technique [26].

Some technical challenges are common to abdominal and orbital imaging and affect the quality of IVIM, such as the presence of motion and susceptibility artefacts [13, 15, 30, 35]. The use of a high-field MRI is preferable in orbital and ocular imaging because of its higher signal-to-noise ratio and contrast-to-noise ratio as well as its better resolution, fully adapted for a small structure like the eye [35, 36]. However, large soft-tissue and air interfaces resulting in susceptibility effects are more pronounced at $3 \mathrm{~T}$ and can provoke image distortions, leading to a loss of image quality [35]. In order to minimize motion artefacts in the orbit, we asked the patients to keep their eyes open during the exam and to stare at a fixed point. The use of a cued-blinking protocol including a regular break every $3 \mathrm{~s}$, in which acquisition is automatically paused and the subject is instructed to blink, might be another strategy to reduce motion artefacts [37]. We also used parallel imaging techniques to decrease these artefacts, and bipolar diffusion gradients to attenuate eddy currents intrinsic to the process. Good visual quality of the sequence was determined in all of our patients by the two readers, and the estimated SNR at $b=$ $2,000 \mathrm{~s} / \mathrm{mm}^{2}$ was good, almost twice the minimal SNR recommended for reliable IVIM imaging [10]. No patient had to be secondarily excluded from the study because of artefacts masking or distorting orbital tumours.

Regarding the optimal type of ROI for analysing an orbital mass, the test-retest repeatability and the inter-observer agreements were slightly better with the use of a large freehand ROI encompassing the largest area inside the lesion versus a small circular ROI, especially for the $\mathrm{D}^{*}$ parameter. The careful

Table 3 Test-retest intraclass correlation coefficients (ICCs), Bland-Altman limits of agreements (BA-Las), Bias and coefficients of variation (CVs) of intravoxel incoherent motion (IVIM)-diffusion-weighted imaging (DWI) values for each anatomical region

\begin{tabular}{|c|c|c|c|c|c|c|c|c|c|}
\hline & & ROI 1 & ROI 2 & ROI 3 & ROI 4 & ROI 5 & ROI 6 & ROI 7 & Mean of all ROI \\
\hline \multirow[t]{4}{*}{$\begin{array}{l}\text { ICC (mean) } \\
{[95 \% \mathrm{CI}]}\end{array}$} & $\mathrm{ADC}$ & $\begin{array}{l}0.96 \\
{[0.91-0.98]}\end{array}$ & $\begin{array}{l}0.95 \\
{[0.87-0.98]}\end{array}$ & $\begin{array}{l}0.94 \\
{[0.85-0.97]}\end{array}$ & $\begin{array}{l}0.54 \\
{[0-0.81]}\end{array}$ & $\begin{array}{l}0.75 \\
{[0.39-0.90]}\end{array}$ & $\begin{array}{l}0.89 \\
{[0.70-0.96]}\end{array}$ & $\begin{array}{l}0.77 \\
{[0.45-0.91]}\end{array}$ & $\begin{array}{l}0.87 \\
{[0.82-0.90]}\end{array}$ \\
\hline & $\mathrm{D}$ & $\begin{array}{l}0.94 \\
{[0.86-0.98]}\end{array}$ & $\begin{array}{l}0.93 \\
{[0.83-0.97]}\end{array}$ & $\begin{array}{l}0.86 \\
{[0.67-0.94]}\end{array}$ & $\begin{array}{l}0.72 \\
{[0.35-0.88]}\end{array}$ & $\begin{array}{l}0.71 \\
{[0.28-0.88]}\end{array}$ & $\begin{array}{l}0.94 \\
{[0.85-0.97]}\end{array}$ & $\begin{array}{l}0.59 \\
{[0 ; 0.83]}\end{array}$ & $\begin{array}{l}0.90 \\
{[0.87-0.93]}\end{array}$ \\
\hline & $\mathrm{PF}$ & $\begin{array}{l}0.91 \\
{[0.78-0.96]}\end{array}$ & $\begin{array}{l}0.90 \\
{[0.77-0.96]}\end{array}$ & $\begin{array}{l}0.91 \\
{[0.79-0.96]}\end{array}$ & $\begin{array}{l}0.75 \\
{[0.40-0.90]}\end{array}$ & $\begin{array}{l}0.76 \\
{[0.41-0.90]}\end{array}$ & $\begin{array}{l}0.86 \\
{[0.64-0.94]}\end{array}$ & $\begin{array}{l}0.90 \\
{[0.77-0.96]}\end{array}$ & $\begin{array}{l}0.87 \\
{[0.83-0.91]}\end{array}$ \\
\hline & $\mathrm{D}^{*}$ & $\begin{array}{l}0.84 \\
{[0.62-0.93]}\end{array}$ & $\begin{array}{l}0.65 \\
{[0.15-0.86]}\end{array}$ & $\begin{array}{l}0.75 \\
{[0.41-0.90]}\end{array}$ & $\begin{array}{l}0.35 \\
{[0 ; 0.73]}\end{array}$ & $\begin{array}{l}0.32 \\
{[0-0.72]}\end{array}$ & $\begin{array}{l}0.76 \\
{[0.43-0.90]}\end{array}$ & $\begin{array}{l}0.78 \\
{[0.46-0.91]}\end{array}$ & $\begin{array}{l}0.73 \\
{[0.63-0.80]}\end{array}$ \\
\hline \multirow[t]{4}{*}{ BA-LA } & $\mathrm{ADC}$ & {$[-0.29-0.26]$} & {$[-0.35-0.35]$} & {$[-0.61-0.75]$} & {$[-1.48-1.60]$} & {$[-0.52-0.55]$} & {$[-0.44-0.26]$} & {$[-0.13-0.13]$} & {$[-0.69-0.70]$} \\
\hline & $\mathrm{D}$ & {$[-0.28-0.25]$} & {$[-0.36-0.27]$} & {$[-0.36-0.45]$} & {$[-0.48-0.35]$} & {$[-0.45-0.45]$} & {$[-0.12-0.13]$} & {$[-0.10-0.11]$} & {$[-0.33-0.31]$} \\
\hline & $\mathrm{PF}$ & {$[-0.08-0.08]$} & {$[-0.10-0.10]$} & {$[-0.09-0.10]$} & {$[-0.15-0.17]$} & {$[-0.12-0.13]$} & {$[-0.12-0.08]$} & {$[-0.06-0.07]$} & [-15.9-14.7] \\
\hline & $\mathrm{D}^{*}$ & {$[-11.8-13.2]$} & [-23.1-20.9] & {$[-17.6-12.0]$} & {$[-14.7-17.7]$} & {$[-15.6-16.3]$} & {$[-12.3-8.0]$} & {$[-13.2-11.9]$} & {$[-0.10-0.11]$} \\
\hline \multirow[t]{4}{*}{$\begin{array}{l}\text { Bias (mean) } \\
{[95 \% \mathrm{CI}]}\end{array}$} & $\mathrm{ADC}$ & $\begin{array}{l}-0.01 \\
{[-0.08-0.05]}\end{array}$ & $\begin{array}{l}0.00 \\
{[-0.08-0.08]}\end{array}$ & $\begin{array}{l}0.07 \\
{[-0.09-0.22]}\end{array}$ & $\begin{array}{l}0.06 \\
{[-0.28-0.41]}\end{array}$ & $\begin{array}{l}0.01 \\
{[-0.11-0.14]}\end{array}$ & $\begin{array}{l}-0.09 \\
{[-0.17-0.01]}\end{array}$ & $\begin{array}{l}0 \\
{[-0.03-0.03]}\end{array}$ & $\begin{array}{l}0.01 \\
{[-0.05-0.06]}\end{array}$ \\
\hline & $\mathrm{D}$ & $\begin{array}{l}-0.02 \\
{[-0.08-0.04]}\end{array}$ & $\begin{array}{l}-0.04 \\
{[-0.11-0.03]}\end{array}$ & $\begin{array}{l}0.05 \\
{[-0.04-0.14]}\end{array}$ & $\begin{array}{l}-0.06 \\
{[-0.16-0.03]}\end{array}$ & $\begin{array}{l}0 \\
{[-0.10-0.10]}\end{array}$ & $\begin{array}{l}0 \\
{[-0.03-0.03]}\end{array}$ & $\begin{array}{l}0 \\
{[-0.02-0.03]}\end{array}$ & $\begin{array}{l}-0.01 \\
{[-0.04-0.02]}\end{array}$ \\
\hline & $\mathrm{PF}$ & $\begin{array}{l}0 \\
{[-0.02-0.02]}\end{array}$ & $\begin{array}{l}0.00 \\
{[-0.02-0.03]}\end{array}$ & $\begin{array}{l}0.00 \\
{[-0.02-0.03]}\end{array}$ & $\begin{array}{l}0.01 \\
{[-0.02-0.05]}\end{array}$ & $\begin{array}{l}0.01 \\
{[-0.02-0.03]}\end{array}$ & $\begin{array}{l}-0.02 \\
{[-0.04-0.00]}\end{array}$ & $\begin{array}{l}0.01 \\
{[-0.01-0.02]}\end{array}$ & $\begin{array}{l}0 \\
{[-0.01-0.01]}\end{array}$ \\
\hline & $\mathrm{D}^{*}$ & $\begin{array}{l}0.71 \\
{[-2.13-3.54]}\end{array}$ & $\begin{array}{l}-1.1 \\
{[-6.08-3.89]}\end{array}$ & $\begin{array}{l}-2.78 \\
{[-6.14-0.57]}\end{array}$ & $\begin{array}{l}1.50 \\
{[-2.17-5.16]}\end{array}$ & $\begin{array}{l}0.35 \\
{[-3.26-3.96]}\end{array}$ & $\begin{array}{l}-2.15 \\
{[-4.45-0.15]}\end{array}$ & $\begin{array}{l}-0.64 \\
{[-3.48-2.19]}\end{array}$ & $\begin{array}{l}-0.59 \\
{[-1.83-0.65]}\end{array}$ \\
\hline \multirow[t]{4}{*}{ CV (mean) (SD) } & $\mathrm{ADC}$ & $0.21(0.06)$ & $0.12(0.05)$ & $0.18(0.06)$ & $0.22(0.06)$ & $0.22(0.07)$ & $0.33(0.13)$ & $0.23(0.06)$ & $0.22(0.09)$ \\
\hline & $\mathrm{D}$ & $0.23(0.06)$ & $0.14(0.05)$ & $0.19(0.06)$ & $0.25(0.07)$ & $0.25(0.06)$ & $0.29(0.06)$ & $0.22(0.05)$ & $0.22(0.07)$ \\
\hline & $\mathrm{PF}$ & $0.62(0.18)$ & $0.43(0.17)$ & $0.51(0.15)$ & $0.51(0.13)$ & $0.54(0.1)$ & $0.66(0.11)$ & $0.75(0.14)$ & $0.57(0.17)$ \\
\hline & $\mathrm{D}^{*}$ & $1.5(0.4)$ & $1.1(0.4)$ & $1.3(0.4)$ & $1.3(0.4)$ & $1.3(0.4)$ & $1.6(0.2)$ & $1.2(0.2)$ & $1.3(0.4)$ \\
\hline
\end{tabular}

$C I$ confidence interval, $A D C$ apparent diffusion coefficient, $D$ 'true' diffusion coefficient, $D^{*}$ pseudodiffusion coefficient, $f$ perfusion fraction, $R O I$ region of interest 
Table 4 Interobserver repeatability agreement intraclass correlation coefficients (ICCs), Bland-Altman limits of agreements (BA-Las), Bias and coefficients of variation (CVs) of intravoxel incoherent motion (IVIM)-diffusion-weighted imaging (DWI) values for each anatomical region

\begin{tabular}{|c|c|c|c|c|c|c|c|c|c|}
\hline & & ROI 1 & ROI 2 & ROI 3 & ROI 4 & ROI 5 & ROI 6 & ROI 7 & Mean of all ROI \\
\hline \multirow[t]{4}{*}{$\begin{array}{l}\text { ICC (mean) } \\
{[95 \% \mathrm{CI}]}\end{array}$} & $\mathrm{ADC}$ & $\begin{array}{l}0.95 \\
{[0.86-0.98]}\end{array}$ & $\begin{array}{l}0.88 \\
{[0.70-0.95]}\end{array}$ & $\begin{array}{l}0.80 \\
{[0.52-0.92]}\end{array}$ & $\begin{array}{l}0.97 \\
{[0.91-0.99]}\end{array}$ & $\begin{array}{l}0.88 \\
{[0.70-0.95]}\end{array}$ & $\begin{array}{l}0.88 \\
{[0.62-0.96]}\end{array}$ & $\begin{array}{l}0.57 \\
{[0-0.82]}\end{array}$ & $\begin{array}{l}0.95 \\
{[0.93-0.96]}\end{array}$ \\
\hline & $\mathrm{D}$ & $\begin{array}{l}0.93 \\
{[0.83-0.97]}\end{array}$ & $\begin{array}{l}0.82 \\
{[0.56-0.93]}\end{array}$ & $\begin{array}{l}0.84 \\
{[0.60-0.93]}\end{array}$ & $\begin{array}{l}0.43 \\
{[0-0.77]}\end{array}$ & $\begin{array}{l}0.88 \\
{[0.70-0.95]}\end{array}$ & $\begin{array}{l}0.84 \\
{[0.39-0.94]}\end{array}$ & $\begin{array}{l}0.63 \\
{[0.12-0.85]}\end{array}$ & $\begin{array}{l}0.88 \\
{[0.83-0.91]}\end{array}$ \\
\hline & $f$ & $\begin{array}{l}0.94 \\
{[0.85-0.98]}\end{array}$ & $\begin{array}{l}0.86 \\
{[0.65-0.94]}\end{array}$ & $\begin{array}{l}0.90 \\
{[0.71-0.96]}\end{array}$ & $\begin{array}{l}0.78 \\
{[0.46-0.91]}\end{array}$ & $\begin{array}{l}0.66 \\
{[0.18-0.86]}\end{array}$ & $\begin{array}{l}0.83 \\
{[0-0.95]}\end{array}$ & $\begin{array}{l}0.81 \\
{[0.54-0.92]}\end{array}$ & $\begin{array}{l}0.85 \\
{[0.78-0.89]}\end{array}$ \\
\hline & $\mathrm{D}^{*}$ & $\begin{array}{l}0.90 \\
{[0.77-0.96]}\end{array}$ & $\begin{array}{l}0.71 \\
{[0.31-0.88]}\end{array}$ & $\begin{array}{l}0.84 \\
{[0.60-0.93]}\end{array}$ & $\begin{array}{l}0.66 \\
{[0.18-0.86]}\end{array}$ & $\begin{array}{l}0.61 \\
{[0.01-0.84]}\end{array}$ & $\begin{array}{l}0.62 \\
{[0-0.87]}\end{array}$ & $\begin{array}{l}0.66 \\
{[0.18-0.86]}\end{array}$ & $\begin{array}{l}0.76 \\
{[0.67-0.83]}\end{array}$ \\
\hline \multirow[t]{4}{*}{ BA-LA } & $\mathrm{ADC}$ & {$[-0.30-0.29]$} & {$[-0.48-0.38]$} & {$[-0.56-0.44]$} & {$[-0.45-0.27]$} & {$[-0.39-0.39]$} & {$[-0.25-0.48]$} & {$[-0.15-0.21]$} & {$[-0.39-0.38]$} \\
\hline & $\mathrm{D}$ & {$[-0.26-0.27]$} & {$[-0.44-0.39]$} & {$[-0.32-0.23]$} & {$[-0.61-0.48]$} & {$[-0.30-0.28]$} & {$[-0.23-0.10]$} & {$[-0.07-0.11]$} & {$[-0.35-0.30]$} \\
\hline & $f$ & {$[-0.06-0.07]$} & {$[-0.12-0.12]$} & {$[-0.06-0.10]$} & {$[-0.14-0.17]$} & {$[-0.12-0.17]$} & {$[-0.03-0.12]$} & {$[-0.08-0.09]$} & {$[-0.09-0.13]$} \\
\hline & $\mathrm{D}^{*}$ & {$[-10.5-8.6]$} & [-22.9-16.5] & {$[-12.3-12.1]$} & {$[-8.8-13.3]$} & {$[-7.2-13.8]$} & {$[-5.8-16.7]$} & {$[-17.2-13.2]$} & {$[-13.4-14.8]$} \\
\hline \multirow[t]{4}{*}{$\begin{array}{l}\text { Bias (mean) } \\
{[95 \% \mathrm{CI}]}\end{array}$} & $\mathrm{ADC}$ & $\begin{array}{l}0 \\
{[-0.07-0.07]}\end{array}$ & $\begin{array}{l}-0.05 \\
{[-0.15-0.05]}\end{array}$ & $\begin{array}{l}-0.06 \\
{[-0.18-0.06]}\end{array}$ & $\begin{array}{l}-0.09 \\
{[-0.18-0.01]}\end{array}$ & $\begin{array}{l}0 \\
{[-0.09-0.09]}\end{array}$ & $\begin{array}{l}0.11 \\
{[0.03-0.20]}\end{array}$ & $\begin{array}{l}0.03 \\
{[-0.01-0.07]}\end{array}$ & $\begin{array}{l}-0.01 \\
{[-0.04-0.02]}\end{array}$ \\
\hline & $\mathrm{D}$ & $\begin{array}{l}0.01 \\
{[-0.05-0.07]}\end{array}$ & $\begin{array}{l}-0.02 \\
{[-0.12-0.07]}\end{array}$ & $\begin{array}{l}-0.05 \\
{[-0.11-0.02]}\end{array}$ & $\begin{array}{l}-0.06 \\
{[-0.19-0.06]}\end{array}$ & $\begin{array}{l}-0.01 \\
{[-0.08-0.06]}\end{array}$ & $\begin{array}{l}-0.06 \\
{[-0.1--0.03]}\end{array}$ & $\begin{array}{l}0.02 \\
{[0.00-0.04]}\end{array}$ & $\begin{array}{l}-0.03 \\
{[-0.05-0.00]}\end{array}$ \\
\hline & $f$ & $\begin{array}{l}0 \\
{[-0.01-0.02]}\end{array}$ & $\begin{array}{l}0 \\
{[-0.03-0.03]}\end{array}$ & $\begin{array}{l}0.02 \\
{[0-0.04]}\end{array}$ & $\begin{array}{l}0.02 \\
{[-0.02-0.05]}\end{array}$ & $\begin{array}{l}0.02 \\
{[-0.01-0.05]}\end{array}$ & $\begin{array}{l}0.05 \\
{[0.03-0.06]}\end{array}$ & $\begin{array}{l}0.01 \\
{[-0.01-0.03]}\end{array}$ & $\begin{array}{l}0.02 \\
{[0.01-0.03]}\end{array}$ \\
\hline & $\mathrm{D}^{*}$ & $\begin{array}{l}-0.98 \\
{[-3.20-1.24]}\end{array}$ & $\begin{array}{l}-3.20 \\
{[-7.78-1.38]}\end{array}$ & $\begin{array}{l}-0.10 \\
{[-2.94-2.74]}\end{array}$ & $\begin{array}{l}2.28 \\
{[-0.29-4.84]}\end{array}$ & $\begin{array}{l}3.31 \\
{[0.87-5.76]}\end{array}$ & $\begin{array}{l}5.43 \\
{[2.82-8.04]}\end{array}$ & $\begin{array}{l}-1.96 \\
{[-5.49-1.56]}\end{array}$ & $\begin{array}{l}0.68 \\
{[-0.49-1.85]}\end{array}$ \\
\hline
\end{tabular}

$C I$ confidence interval, $A D C$ apparent diffusion coefficient, $D$ 'true' diffusion coefficient, $D^{*}$ pseudodiffusion coefficient, $f$ perfusion fraction, $R O I$ region of interest

delineation of the entire lesion appeared to be more robust for analysis. These results are in agreement with other studies which evaluated the influence of the type, size, and position of tumour ROI on perfusion values, with a greater reliability and repeatability of large ROIs outlining entire tumours [38].

We investigated which intra-orbital or extra-orbital structures might be a good structure of reference for the quantitative use of IVIM values when diagnosing orbital diseases, if normalization of parameters between subjects was needed, such as it has been proposed in gynaecological tumours (using the outer myometrium) [39] or brain tumours (using a contralateral healthy area) [40]. The repeatability of the ADC and D parameters in the temporal muscle was excellent, with a low $\mathrm{CV}$ and a high ICC. This muscle is bigger than extra-ocular muscles or the lacrimal gland and is therefore easier to see. It is an immobile structure and it is less prone to image distortion compared to orbital structures. Moreover, it is almost always preserved, even in case of orbital diseases involving both eyes, thus being more reliable as a structure of reference.

In our study, D values were consistently lower than the $\mathrm{ADC}$ values despite a clear linear relation between these two values, strongly supporting the existence of both a diffusional component in the orbital tumours evaluated by the $\mathrm{D}$ value and a non-negligible perfusional component evaluated by $f$ and $\mathrm{D}^{*}$. However, perfusion-related parameter changes will require caution in their interpretation in future studies considering their poor repeatabilities. On the other hand, ADC and D showed a good repeatability in our study, suggesting that these parameters might be more reliable and reproducible quantitative biomarkers to characterise orbital tumours, quantify the severity of the disease and predict its course, but also to evaluate therapeutic responses under treatments like chemotherapy for lymphomas or prototherapy for ocular melanomas.

Our study had some limitations. First, we included a relatively small number of patients recruited from a single centre, thus preventing us from performing analysis of the reproducibility of the IVIM technique on different MR devices or centres, which would be an important step before further large multicentre studies. Second, the time delay between the first and second IVIM acquisition was short, limiting the ability to evaluate all potential factors of variability and minimising the effects of other variance components. Third, we considered the orbit contralateral to the side of pathology as healthy, although most of the cases imaged were inflammatory diseases or lymphomas, which can affect both sides.

In conclusion, our study showed the feasibility and robustness of quantitative assessment of IVIM parameters in the orbit. Test-retest repeatability in orbital tumours was good for $\mathrm{ADC}$ and $\mathrm{D}$, but was poor for $f$ and especially for $\mathrm{D}^{*}$, whereas the inter-observer agreement repeatability was almost perfect for all values. Further research would be needed to improve MR acquisition and to increase the repeatability of perfusion-related IVIM parameters, and clinical studies must be performed to assess its potential utility in clinical practice. 
Acknowledgements Laura McMaster provided professional Englishlanguage medical editing of this article.

\section{Compliance with ethical standards}

Guarantor The scientific guarantor of this publication is A. Lecler, Department of Radiology, Fondation Ophtalmologique Adolphe de Rothschild, Paris, France.

Conflict of interest The authors of this manuscript declare no relationships with any companies whose products or services may be related to the subject matter of the article.

Funding The authors state that this work has not received any funding.

Statistics and biometry One of the authors has significant statistical expertise : H. Picard, MD, Clinical Research Unit, Fondation Ophtalmologique Adolphe de Rothschild, Paris, France

Informed consent Written informed consent was obtained from all subjects (patients) in this study.

Ethical approval Institutional Review Board approval was obtained. (IRB 2015-A00364-45)

\section{Methodology \\ - prospective \\ - diagnostic or prognostic study \\ - performed at one institution}

Open Access This article is distributed under the terms of the Creative Commons Attribution 4.0 International License (http:// creativecommons.org/licenses/by/4.0/), which permits unrestricted use, distribution, and reproduction in any medium, provided you give appropriate credit to the original author(s) and the source, provide a link to the Creative Commons license, and indicate if changes were made.

\section{References}

1. Le Bihan D, Breton E, Lallemand D et al (1986) MR imaging of intravoxel incoherent motions: application to diffusion and perfusion in neurologic disorders. Radiology 161:401-407

2. Le Bihan D (1988) Intravoxel incoherent motion imaging using steady-state free precession. Magn Reson Med 7:346-351

3. Koh D-M, Collins DJ, Orton MR (2011) Intravoxel incoherent motion in body diffusion-weighted MRI: reality and challenges. AJR Am J Roentgenol 196:1351-1361

4. Luciani A, Vignaud A, Cavet $M$ et al (2008) Liver cirrhosis: intravoxel incoherent motion MR imaging-pilot study. Radiology 249:891-899

5. Patel J, Sigmund EE, Rusinek H et al (2010) Diagnosis of cirrhosis with intravoxel incoherent motion diffusion MRI and dynamic contrast-enhanced MRI alone and in combination: preliminary experience. J Magn Reson Imaging JMRI 31:589-600

6. Lemke A, Laun FB, Klauss M et al (2009) Differentiation of pancreas carcinoma from healthy pancreatic tissue using multiple bvalues: comparison of apparent diffusion coefficient and intravoxel incoherent motion derived parameters. Invest Radiol 44:769-775

7. Thoeny HC, Binser T, Roth B et al (2009) Noninvasive assessment of acute ureteral obstruction with diffusion-weighted MR imaging: a prospective study. Radiology 252:721-728
8. Döpfert J, Lemke A, Weidner A, Schad LR (2011) Investigation of prostate cancer using diffusion-weighted intravoxel incoherent motion imaging. Magn Reson Imaging 29:1053-1058

9. Bisdas S, Koh TS, Roder C et al (2013) Intravoxel incoherent motion diffusion-weighted MR imaging of gliomas: feasibility of the method and initial results. Neuroradiology 55:1189-1196

10. Wu W-C, Chen Y-F, Tseng H-M et al (2015) Caveat of measuring perfusion indexes using intravoxel incoherent motion magnetic resonance imaging in the human brain. Eur Radiol 25:2485-2492

11. Dyvorne H, Jajamovich $\mathrm{G}$, Kakite $\mathrm{S}$ et al (2014) Intravoxel incoherent motion diffusion imaging of the liver: optimal b-value subsampling and impact on parameter precision and reproducibility. Eur J Radiol 83:2109-2113

12. Moteki T, Horikoshi H (2006) Evaluation of hepatic lesions and hepatic parenchyma using diffusion-weighted echo-planar MR with three values of gradient b-factor. J Magn Reson Imaging JMRI 24: $637-645$

13. Kakite S, Dyvorne H, Besa C et al (2015) Hepatocellular carcinoma: short-term reproducibility of apparent diffusion coefficient and intravoxel incoherent motion parameters at 3.0T. J Magn Reson Imaging JMRI 41:149-156

14. Sigmund EE, Vivier P-H, Sui D et al (2012) Intravoxel incoherent motion and diffusion-tensor imaging in renal tissue under hydration and furosemide flow challenges. Radiology 263:758-769

15. Barbieri S, Donati OF, Froehlich JM, Thoeny HC (2015) Comparison of Intravoxel Incoherent Motion Parameters across MR Imagers and Field Strengths: Evaluation in Upper Abdominal Organs. Radiology 279:784-794

16. Politi LS, Forghani R, Godi C et al (2010) Ocular adnexal lymphoma: diffusion-weighted $\mathrm{mr}$ imaging for differential diagnosis and therapeutic monitoring. Radiology 256:565-574

17. Sepahdari AR, Aakalu VK, Setabutr $P$ et al (2010) Indeterminate orbital masses: restricted diffusion at MR imaging with echo-planar diffusion-weighted imaging predicts malignancy. Radiology 256: 554-564

18. Haradome K, Haradome H, Usui Y et al (2014) Orbital lymphoproliferative disorders (OLPDs): value of MR imaging for differentiating orbital lymphoma from benign OPLDs. AJNR Am J Neuroradiol 35:1976-1982

19. $\mathrm{Xu} \mathrm{X}-\mathrm{Q}, \mathrm{Hu} \mathrm{H}$, Liu $\mathrm{H}$ et al (2016) Benign and malignant orbital lymphoproliferative disorders: Differentiating using multiparametric MRI at 3.0T. J Magn Reson Imaging JMRI 45:167-176

20. Ro S-R, Asbach P, Siebert E et al (2016) Characterization of orbital masses by multiparametric MRI. Eur J Radiol 85:324-336

21. Steens SCA, Admiraal-Behloul F, Schaap JA et al (2004) Reproducibility of brain ADC histograms. Eur Radiol 14:425-430

22. Reeder SB, Wintersperger BJ, Dietrich O et al (2005) Practical approaches to the evaluation of signal-to-noise ratio performance with parallel imaging: application with cardiac imaging and a 32channel cardiac coil. Magn Reson Med 54:748-754

23. Bland JM, Altman DG (1986) Statistical methods for assessing agreement between two methods of clinical measurement. Lancet Lond Engl 1:307-310

24. Barnhart HX, Barboriak DP (2009) Applications of the repeatability of quantitative imaging biomarkers: a review of statistical analysis of repeat data sets. Transl Oncol 2:231-235

25. Raunig DL, McShane LM, Pennello G et al (2015) Quantitative imaging biomarkers: a review of statistical methods for technical performance assessment. Stat Methods Med Res 24:27-67

26. Sullivan DC, Obuchowski NA, Kessler LG et al (2015) Metrology Standards for Quantitative Imaging Biomarkers. Radiology 277: 813-825

27. Poste $\mathrm{G}$ (2011) Bring on the biomarkers. Nature 469:156-157

28. Hoang JK, Choudhury KR, Chang J et al (2014) Diffusionweighted imaging for head and neck squamous cell carcinoma: 
quantifying repeatability to understand early treatment-induced change. AJR Am J Roentgenol 203:1104-1108

29. Barbieri S, Donati OF, Froehlich JM, Thoeny HC (2015) Impact of the calculation algorithm on biexponential fitting of diffusionweighted MRI in upper abdominal organs. Magn Reson Med 75: 2175-2184

30. Lee Y, Lee SS, Kim N et al (2015) Intravoxel incoherent motion diffusion-weighted MR imaging of the liver: effect of triggering methods on regional variability and measurement repeatability of quantitative parameters. Radiology 274:405-415

31. Jerome NP, Orton MR, d'Arcy JA et al (2014) Comparison of freebreathing with navigator-controlled acquisition regimes in abdominal diffusion-weighted magnetic resonance images: Effect on ADC and IVIM statistics. J Magn Reson Imaging JMRI 39:235-240

32. Neil JJ, Bretthorst GL (1993) On the use of Bayesian probability theory for analysis of exponential decay data: an example taken from intravoxel incoherent motion experiments. Magn Reson Med 29:642-647

33. Sukstanskii AL, Bretthorst GL, Chang YVet al (1997) (2007) How accurately can the parameters from a model of anisotropic $3 \mathrm{He}$ gas diffusion in lung acinar airways be estimated? Bayesian view. J Magn Reson San Diego Calif 184:62-71

34. Kessler LG, Barnhart HX, Buckler AJ et al (2015) The emerging science of quantitative imaging biomarkers terminology and definitions for scientific studies and regulatory submissions. Stat Methods Med Res 24:9-26

35. Chang KJ, Kamel IR, Macura KJ, Bluemke DA (2008) 3.0-T MR imaging of the abdomen: comparison with 1.5 T. Radiogr Rev Publ Radiol Soc N Am Inc 28:1983-1998

36. Erb-Eigner K, Warmuth C, Taupitz M et al (2013) Impact of magnetic field strength and receiver coil in ocular MRI: a phantom and patient study. RöFo Fortschritte Auf Dem Geb Röntgenstrahlen Nukl 185:830-837

37. Beenakker J-WM, Ferreira TA, Soemarwoto KP et al (2016) Clinical evaluation of ultra-high-field MRI for three-dimensional visualisation of tumour size in uveal melanoma patients, with direct relevance to treatment planning. Magma N Y N 29:571-577

38. Goh V, Schaeffter T, Leach M (2013) Reproducibility of dynamic contrast-enhanced MR imaging: why we should care. Radiology 266:698-700

39. Thomassin-Naggara I, Daraï E, Cuenod CA et al (2008) Dynamic contrast-enhanced magnetic resonance imaging: a useful tool for characterizing ovarian epithelial tumors. J Magn Reson Imaging JMRI 28:111-120

40. Kickingereder P, Wiestler B, Sahm F et al (2014) Primary central nervous system lymphoma and atypical glioblastoma: multiparametric differentiation by using diffusion-, perfusion-, and susceptibility-weighted MR imaging. Radiology 272:843-850 